\title{
Does the natural carcinogen ptaquiloside degrade readily in groundwater?
}

\author{
Jane S. Wu ${ }^{1}$, Frederik Clauson-Kaas ${ }^{1}$, Dan Nybro Lindqvist ${ }^{2}$, Lars Holm Rasmussen ${ }^{2 *} \mathbb{C}$, Bjarne W. Strobel ${ }^{1}$ \\ and Hans Christian Bruun Hansen ${ }^{1}$
}

\begin{abstract}
Background: Ptaquiloside (PTA) is a natural carcinogen found in bracken ferns. PTA is released from the plants via soil to surface and groundwaters from where humans can be exposed via drinking water. Primary degradation of PTA is due to hydrolysis with formation of pterosin B (PTB). Temperature and pH determine the rate of hydrolysis under pure experimental conditions. To assess the applicability of the experimental model to natural groundwaters, PTA degradation kinetics were examined in a range of natural groundwaters at environmentally relevant conditions.

Results: PTA was quantified by UPLC-MS/MS. Over an 80-day study period, PTA half-lives ranged from 6.5 to 47 days (natural $\mathrm{pH} ; 8.0^{\circ} \mathrm{C}$ ). The fastest degradation was observed for the most alkaline groundwaters with $\mathrm{pH}$ of around 8 . Rates of degradation were well predicted using an existing mathematical model for hydrolysis. However, deviations from this model were found, especially at the extremes of the examined pH-range (4.7-8.2). The degree of conversion of PTA to PTB was close to unity around neutral pH. However, at slightly acidic conditions, formation of PTB could only count for $9 \%$ of the degraded PTA, indicating formation of other products.
\end{abstract}

Conclusions: Degradation of PTA in groundwater is determined by $\mathrm{pH}$ and temperature, and PTA can prevail for months under slightly acid to neutral pH conditions. The existing laboratory-based model for PTA hydrolysis is generally applicable for groundwaters but needs further validation at high and low $\mathrm{pH}$.

Keywords: Pterosin B, Bracken fern, Pteridium, Hydrolysis, Cancer, Drinking water

\section{Background}

Ptaquiloside (PTA, Fig. 1) is a naturally occurring illudane glycoside with carcinogenic and mutagenic properties. The group of illudane glycosides comprise PTA and PTA-like compounds like caudatoside, ptesculentoside and hypoloside all sharing the same illudanetype skeleton and a highly reactive cyclopropane moiety responsible for their genotoxicity [1-3]. PTA is the most studied illudane glycoside and is particularly well-studied in bracken ferns (Pteridium spp.), which are classified by WHO/IARC as "...possibly carcinogenic to humans" (Group 2B [4]). In addition, ingestion of bracken causes

\footnotetext{
${ }^{*}$ Correspondence: LHRA@KP.DK

${ }^{2}$ Department of Technology, University College Copenhagen,

Sigurdsgade 26, 2200 Copenhagen, Denmark

Full list of author information is available at the end of the article
}

a number of chronic and acute intoxications among farm animals, of which Bovine Enzootic Haematuria (urinary bladder cancer among bovines) is widespread in bracken infested areas [1,2]. Bracken ferns are an abundant and globally-distributed genus, with the exception of areas with extremely cold or dry conditions. Accordingly, the ferns are found on all continents except for Antarctica. Bracken grow as a natural part of forested ecosystems and as a primary species in bush areas. Within agriculture, bracken often appears as a common weed with invasive properties on grasslands, where dense stands can be found covering huge areas [5].

Humans may come in contact with PTA in a number of ways, e.g., by direct ingestion of bracken, inhalation of spores, or via contaminated milk or water [2, 6-9]. PTA is found in all parts of bracken ferns above as well as below the soil surface. It can be released into the 

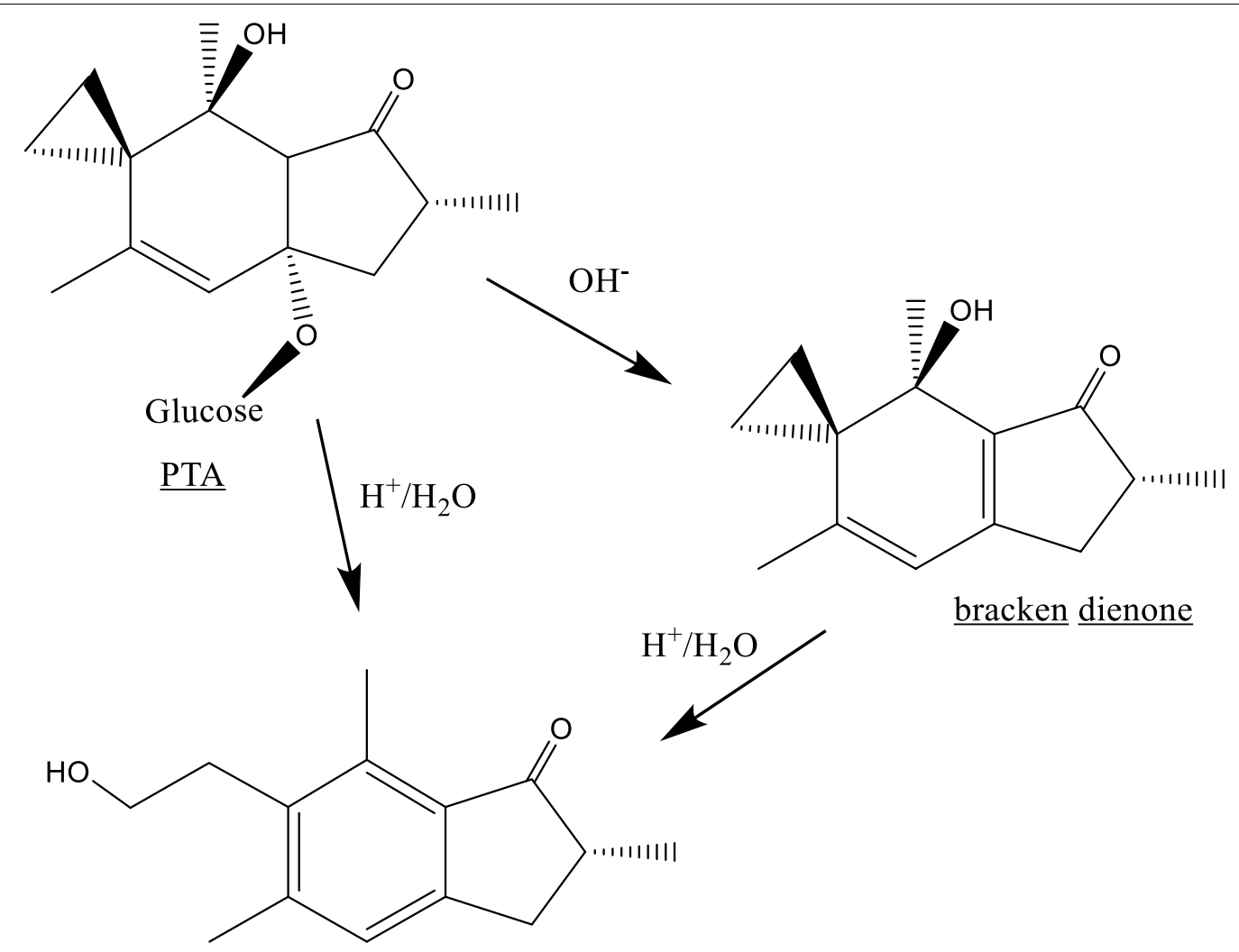

bracken dienone

PTB

Fig. 1 Hydrolysis of ptaquiloside (PTA) and formation of the main metabolites pterosin B (PTB) and the bracken dienone under alkaline and/or acidic conditions. Other metabolites and reaction intermediates may form depending on reaction conditions. Adapted from [1]

environment from living and decaying plant material by rain. Rain will wash off PTA released from the oftenextensive populations of up to hundreds of hectares, which may result in contamination of soils and eventually surface waters and groundwaters. Rain events will result in pulses of PTA entering the environment [10]. However, PTA is also continuously being released from bracken stands into recipients, and baseline levels are encountered in streams in bracken infested areas [10-12]. Recent field based investigations in Denmark, United Kingdom and Ireland have proven the presence of PTA, caudatoside and degradation products in surface and shallow groundwaters in bracken infested areas of up to $2.5 \mu \mathrm{g} / \mathrm{L}$ [10, 12-15]. For humans, it has been shown that consumption of bracken crosiers and/ or the mere fact of living in a bracken infested area can result in a relative risk of 1.5 to 5.5 for developing cancers (esophageal/gastric/upper alimentary tract; [1]). According to the guidelines from The Danish Environmental Protection Agency, the tolerable concentration of PTA in drinking water is approximately $0.015 \mu \mathrm{g} / \mathrm{L}$ [16]. Hence, the recent findings of PTA could prove to be problematic, especially if PTA is stable for longer periods in groundwater.

PTA is sensitive to acid and alkaline hydrolysis, resulting in aromatization and formation of non-carcinogenic pterosin B (PTB). Similar pterosins are found as products of hydrolysis from other illudane glycosides. Hydrolysis of PTA can be described by conventional hydrolysis kinetics under pure experimental conditions $[17,18]$ :

$$
k_{\mathrm{obs}}=k_{A}\left[H^{+}\right]+k_{N}+\frac{k_{B} \times k_{W}}{\left[H^{+}\right]}
$$

where $k_{w}=10^{-14.10}\left(22{ }^{\circ} \mathrm{C}\right.$ [18] $)$ and the $\mathrm{pH}$-dependent rate constants are $k_{A}=25.70 \mathrm{M}^{-1} \mathrm{~h}^{-1}$ (acidic conditions), $k_{N}=9.49 \times 10^{-4} \mathrm{~h}^{-1}$ (neutral conditions), and $k_{B}=4.83 \times 10^{4} \mathrm{M} \mathrm{h}^{-1}$ (alkaline conditions). The rate of hydrolysis has a minimum at $\mathrm{pH} 5.5$ with a window of slow hydrolysis in the $\mathrm{pH}$ range 4.5 to 6.5 . In addition, clay minerals and low temperatures slow down PTA hydrolysis. Microbial degradation has a pronounced effect on PTA degradation making it most stable in environments with low microbiological activity $[17,19,20]$. 
Thus, in regions with clay-containing aquifers and/or acid groundwaters in addition to low temperatures and low microbiological activity in aquifers, PTA is expected to hydrolyze slowly. Groundwater may, therefore, be a source of PTA exposure for humans in bracken infested areas. Recently, Skrbic and co-workers (2020) found PTA and caudatoside and pterosins in shallow groundwater wells and proved the hypothesis to be true [14, 21].

The aim of this study was to quantify the stability of PTA under near-natural conditions in Danish groundwaters and to test if the hydrolysis kinetics found in the laboratory (Eq. 1) apply to true groundwaters to gain a better understanding of PTA degradation dynamics and to model PTA dissipation in aquifers with acid to weakly alkaline $\mathrm{pH}$.

\section{Materials and methods Chemicals}

Ammonium acetate, formic acid (MS grade), glacial acetic acid, trifluoroacetic acid, methanol (MS-grade), and polyamide- 6 resin were supplied by Sigma-Aldrich (Steinheim, Germany). Sodium hydroxide was from J.T.Baker (Deventer, the Netherlands). Deionized ultrapure water produced by PURELAB Chorus ultrapure water system (ELGA, France) was used throughout.

PTA for use as standards and in experiments was isolated from dried bracken fronds by the method described by Clauson-Kaas et al. [22], based on the work of Rasmussen et al. [20]. In short, an aqueous extract of the bracken fronds was purified on self-packed XAD-2 and ChemElut columns, and further purified using preparative HPLC. The process was followed by an additional purification step using a polyamide column to remove potential degradation products formed during storage. The purity of the PTA was $84 \%$ based on quantitative ${ }^{1} \mathrm{H}$ NMR spectroscopy using 3-(trimethylsilyl)propionic-2,2,3,3-d4 acid sodium salt as internal standard. No contaminants were observed by full-scan MS/UV-VIS spectroscopy of aqueous PTA solutions indicating that the purity below $100 \%$ was due to water absorbed by the highly hygroscopic purified PTA product.

\section{Stock solution and calibration standards}

PTA stock solutions $(61.4-62.5 \mathrm{mg} / \mathrm{L})$ were prepared from isolated PTA in water and stored at $-18{ }^{\circ} \mathrm{C}$. Stock solutions were completely thawed at room temperature and shaken in connection with preparation of standards and for use in experiments. A $200 \mu \mathrm{g} / \mathrm{L}$ PTB solution was made by 1:1 conversion of a PTA stock solution following the methods of Aranha et al. and Rasmussen \& Pedersen $[23,24]$. In brief, an aliquot of a PTA stock was diluted in $\mathrm{H}_{2} \mathrm{O}$, made alkaline with sodium hydroxide, incubated in a water bath at $45{ }^{\circ} \mathrm{C}$ for $60 \mathrm{~min}$, then reacted into PTB on addition of trifluoroacetic acid. The solvent composition was adjusted to $40 \%$ methanol $(\mathrm{v} / \mathrm{v})$ to obtain $200 \mu \mathrm{g} / \mathrm{L}$ PTB. Calibration standards of PTA and PTB in the range 1-40 $\mu \mathrm{g} / \mathrm{L}$ were prepared in $40 \%$ methanol $(\mathrm{v} / \mathrm{v})$ in $2 \mathrm{~mL}$ amber LC vials. All standards and samples were kept at $-18{ }^{\circ} \mathrm{C}$ when not in use which has proved efficient for stability of standards [22].

\section{Collection of groundwater samples}

Five groundwaters were chosen to represent the natural variation of deep groundwater chemical composition in Denmark, in particular with respect to pH (Fig. 2). The raw untreated groundwaters were collected from individual wells supplying public waterworks in the Eastern (Zealand) and Western (Jutland) regions of Denmark (except Ermelund, where the abstracted water is mixed from several wells). The temporal variation of the water chemistry is low and to a large extent determined by the aquifer geochemistry. The chemical composition of the waters is shown in Table 1 [25].

The lower $\mathrm{pH}$ water types (Agerbaek, Varde, and to some extent Hovborg) are congregated around the area of Western Jutland, which is characterized by sandy aquifer sediments, though the Varde area is also characterized by the presence of some clay. The higher $\mathrm{pH}$ water samples (Ermelund and Villingebaek) were taken from the island of Zealand, an area characterized by fine and silty deposits and limestone aquifers. The acid waters are characterized by high contents of dissolved carbon dioxide and higher solubility of metal cations. On the other hand, the non-acid waters have high alkalinity and hence high hardness due to the simultaneous presence of high concentrations of calcium and magnesium [25]. Anoxic conditions may be present in both acid and alkaline groundwaters giving rise to the presence of iron(II).

The Ermelund water has considerably higher levels of most solutes (except carbon dioxide, oxygen, ammonia + ammonium, iron, and nitrate) compared to the other waters, and accordingly a relatively high amount of evaporation residue. The Zealand waters (Ermelund and Villingebaek) also have higher levels of dissolved organic carbon ( 2.9 and $2.2 \mathrm{mg} / \mathrm{L}$, respectively) and conductivity than their Jutland counterparts. The Varde and Agerbaek water samples have notably higher levels of nitrate. All included waters were raw waters, not yet treated for use.

Raw abstracted water was sampled on two occasions in July 2015. The raw water source was kept running for at least $15 \mathrm{~min}$ before collection in double-acid washed 1 L BlueCap glass bottles (Duran ${ }^{\circledR}$ laboratory bottles, Sigma-Aldrich, Denmark). The bottles were filled and rinsed twice with the raw groundwater before being nearly completely filled (to minimize diffusion of air). Two liters of each water were collected. Each bottle was 

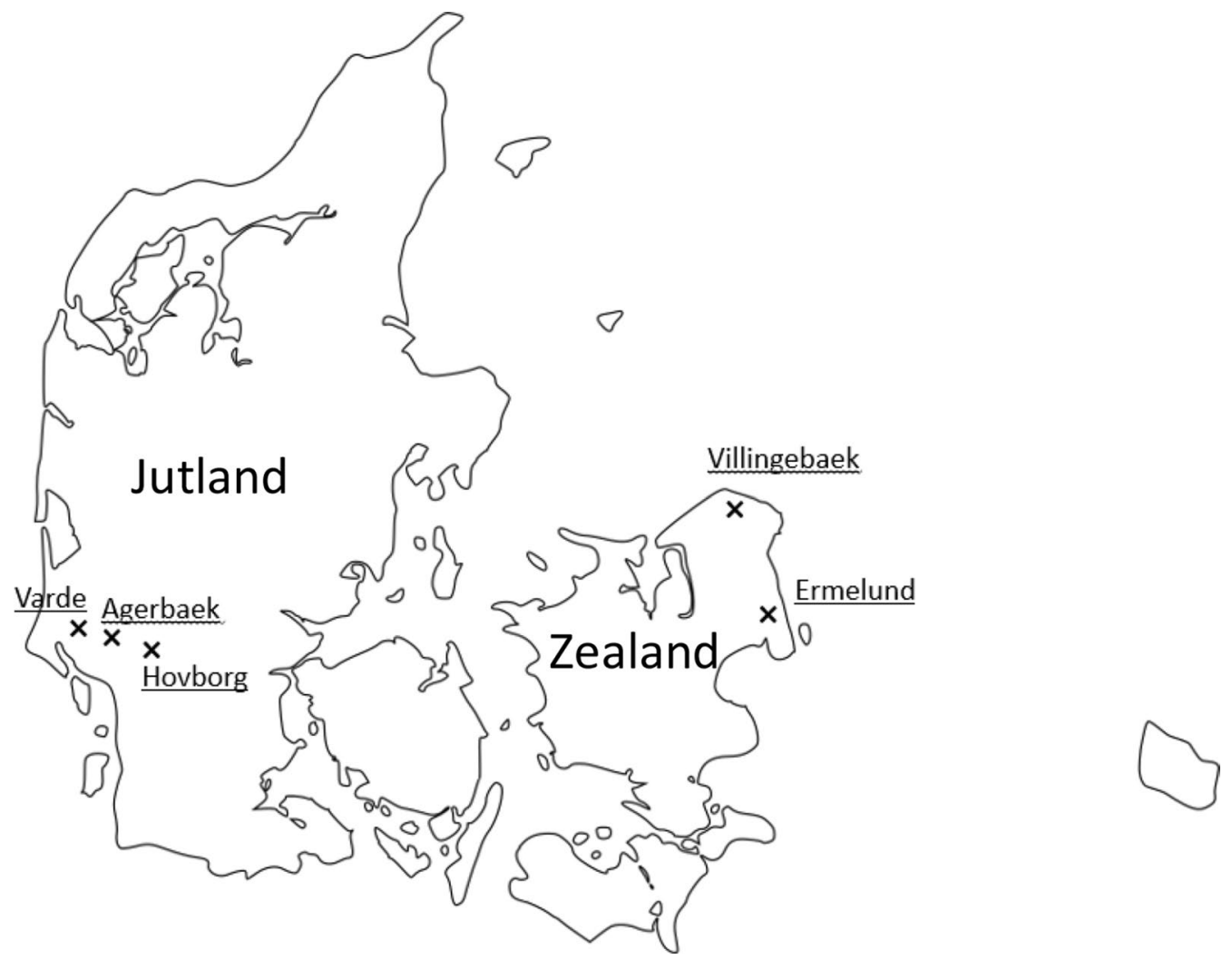

Fig. 2 Map of Denmark with the five groundwater sampling locations (water plants)

covered in aluminum foil to prevent photochemical reactions during transport and storage. The waters were kept in ice-filled buckets during transport and stored in a dark and cool environment $\left(2-5^{\circ} \mathrm{C}\right)$ until use.

Experimental set-up.

For each PTA hydrolysis experiment, PTA was diluted in $100 \mathrm{~mL}$ of groundwater to a starting concentration of about $40 \mu \mathrm{g} / \mathrm{L}$ in $100 \mathrm{~mL}$ double-acid washed BlueCap glass bottles (triplicate; Duran ${ }^{\circledR}$ laboratory bottles, Sigma-Aldrich, Denmark). A Control in pure LC-MS grade water was included, also in triplicate (PURELAB Chorus ultrapure water system, ELGA, France). Each bottle was wrapped in aluminum foil to minimize light exposure that could interfere with PTA degradation. The bottles were stored in a dark refrigerator. A temperature logger (EL-USB-2, Lascar Electronics, Erie, USA) took measurements of refrigerator temperature every $10 \mathrm{~min}$ for the duration of the experiment. The average temperature was $8.0 \pm 1.4{ }^{\circ} \mathrm{C}$ (standard deviation), which reproduces the natural temperature level of the groundwaters [25].

The sampling schedule of the stored waters was as follows: 1-day intervals for the first 5 days, then three, five, and approx. 10-day intervals thereafter for a total duration of 80 days ( $1920 \mathrm{~h}$; all triplicate waters).

A subset of samples collected across the studied groundwaters were analyzed for formation of PTB as well. These were selected at 5 different time points in the experiment (days 13, 19, 49, 69, and 80) from each of the waters, except Villingebaek, where only two samples were included due to undetectable levels of PTA after day 13. The ratio of PTA consumption and PTB (in PTA-equivalents) formation in samples were compared. Each sample was analyzed once in the subset.

\section{Sample preparation and quantification of analytes}

A sample of approx. $2 \mathrm{~mL}$ was removed from each BlueCap bottle at each sampling time point. One $\mathrm{mL}$ of solution was transferred to an $\mathrm{LC}$ vial and the $\mathrm{pH}$ was measured using a Metrohm microelectrode (triplicate measurement). In a separate $2 \mathrm{~mL}$ amber LC vial, $930 \mu \mathrm{L}$ of sample solution was prepared by dilution with $620 \mu \mathrm{L}$ methanol to reach a solvent composition of $40 \%$ methanol, buffered with $23 \mu \mathrm{L}$ of $0.3 \mathrm{M}$ ammonium acetate buffer as suggested by Clauson-Kaas et al. [22] and filtered using a fresh RC-syringe filter $(0.2 \mu \mathrm{m}$, 
Table 1 Raw groundwater sampling locations and chemical composition

\begin{tabular}{|c|c|c|c|c|c|}
\hline Location & Villingebaek & Ermelund & Hovborg & Varde & Agerbaek \\
\hline Coordinates of well & $\begin{array}{l}56^{\circ} 05^{\prime} 49.0^{\prime \prime} \mathrm{N} \\
12^{\circ} 23^{\prime} 55.6^{\prime \prime} \mathrm{E}\end{array}$ & $\begin{array}{l}55^{\circ} 44^{\prime} 29.4^{\prime \prime} \mathrm{N} \\
12^{\circ} 33^{\prime} 04.8^{\prime \prime} \mathrm{E}\end{array}$ & $\begin{array}{l}55^{\circ} 36^{\prime} 35.7^{\prime \prime} \mathrm{N} \\
8^{\circ} 56^{\prime} 27.1^{\prime \prime} \mathrm{E}\end{array}$ & $\begin{array}{l}55^{\circ} 38^{\prime} 09.9^{\prime \prime} \mathrm{N} \\
8^{\circ} 29^{\prime} 45.3^{\prime \prime} \mathrm{E}\end{array}$ & $\begin{array}{l}55^{\circ} 36^{\prime} 50.7^{\prime \prime} \mathrm{N} \\
8^{\circ} 47^{\prime} 08.7^{\prime \prime} \mathrm{E}\end{array}$ \\
\hline $\mathrm{pH}$ & 7.8 & 7.0 & 5.9 & 5.8 & 4.7 \\
\hline Temp $\left({ }^{\circ} \mathrm{C}\right)$ & 9.5 & 11 & 8.3 & 8.5 & 8.1 \\
\hline Conductivity ( mS/m) & 46 & 141 & 12 & 27 & 27 \\
\hline Evaporation residue & 300 & 913 & 87 & 160 & 170 \\
\hline Oxygen & $<0.2$ & 0.2 & 0.7 & 0.5 & 3.0 \\
\hline Carbon dioxide & $<2$ & $<5$ & 30 & 35 & 50 \\
\hline Organic carbon & 2.2 & 2.9 & 0.2 & 0.5 & 0.7 \\
\hline Ammonia + ammonium & 0.62 & 0.01 & 0.08 & 0.04 & 0.01 \\
\hline Calcium & 64 & 173 & 11 & 19 & 12 \\
\hline Iron & 1.2 & $<0.01$ & 2.2 & 0.58 & 1.3 \\
\hline Magnesium & 10 & 22 & 1.5 & 5.8 & 7.9 \\
\hline Manganese & 0.16 & 0.52 & 0.10 & 0.08 & 0.07 \\
\hline Phosphorus & 0.14 & 0.05 & 0.06 & 0.01 & 0.02 \\
\hline Potassium & 2.6 & 26 & 0.92 & 2 & 1.8 \\
\hline Sodium & 23 & 82 & 9.3 & 22 & 19 \\
\hline Bicarbonate & 250 & 452 & 41.2 & 16.1 & 4.3 \\
\hline Chloride & 22 & 190 & 15 & 34 & 34 \\
\hline Fluoride & 0.32 & 0.27 & 0.35 & 0.12 & 0.75 \\
\hline Nitrate & $<0.3$ & 3.35 & $<0.5$ & 17 & 32 \\
\hline Nitrite & 0.011 & 0.046 & $<0.005$ & 0.011 & 0.011 \\
\hline Sulfate & 12 & 54 & 6.9 & 45 & 35 \\
\hline
\end{tabular}

Number of digits as reported [25]

$\varnothing=25 \mathrm{~mm})$ to remove particulates. The filtrates were stored at $-18{ }^{\circ} \mathrm{C}$ until quantification. Blank, non-fortified samples, were included in the experiment for quality control.

Water samples were analyzed by UPLC-MS/MS using $10 \mu \mathrm{L}$ injections (Acquity UPLC I-Class (Waters, Milford); Xevo TQD triple quadrupole mass spectrometer (electrospray ionization; Waters, Milford); Cortecs C18 column $(2.1 \times 50 \mathrm{~mm}$, particle size $1.6 \mu \mathrm{m}$; Waters, Milford) following the method of Clauson-Kaas et al. [22] employing a water-methanol gradient and controlling $\mathrm{pH}$ with a low concentration of formic acid $(0.01 \%(\mathrm{v} / \mathrm{v}))$. The flow rate was $0.450 \mathrm{~mL} / \mathrm{min}$. PTA was monitored as the ion traces $m / z 421.1->241.1$ (quantifier) and $m / z$ 421.1-> 203.1 (qualifier), eluting at $1.40 \mathrm{~min}$; PTB as $\mathrm{m} / z$ 219.1-> 201.1, eluting at $1.80 \mathrm{~min}$ (no stable qualifier). PTA and PTB were quantified by external calibration with seven freshly prepared standards in the range $1-40 \mu \mathrm{g} / \mathrm{L}$ PTA and PTA-equivalents, respectively. The limit of quantification was set as the lowest used standard $(1 \mu \mathrm{g} / \mathrm{L})$, with the same quality control considerations as documented earlier [22]. No significant matrix effects were observed following signal/concentration check of the first data point (Fig. 3).

\section{Quality control-pH and microbial activity}

Over the course of the 80 day $(1920$ h; study period, the average $\mathrm{pH}$ in four groundwater samples had a noteworthy increase from their starting values (Villingebaek: $+0.40 ;$ Ermelund: +0.53 ; Hovborg: +1.06 ; Varde: +1.20$)$. This is attributed to venting of carbon dioxide upon opening of the flasks for sampling. However, Agerbaek, with the highest reported content of $\mathrm{CO}_{2}$ of the waters, had no significant deviation in $\mathrm{pH}$ over the course of the study period indicating that acidification reactions such as oxidation of iron(II) may also have taken place.

Each of the PTA-spiked groundwaters were tested for microbial growth after 62 days $(1490 \mathrm{~h} ; 1 \times, 10 \times$, $100 \times$, and $1000 \times$ dilutions at $30{ }^{\circ} \mathrm{C}$ for $24 \mathrm{~h}$; [26]). Only 5 of 60 plates grew any colonies. In total, four plates from the Control exhibited growth (8 and 4 CFUs at no dilution; 5 and 1 CFUs at $10 \times$ dilution). One plate from Ermelund had a single CFU at no dilution. All other plates were free of visible microbial growth. Thus, it is anticipated that microbial activity had little to no impact on the degradation of PTA in the stored waters. 


\section{Data analysis}

The concentration of PTA in the groundwaters is a function of the rate of abiotic hydrolysis plus any other reactions taking place, including microbial degradation. To determine the rate of PTA hydrolysis, a third-degree polynomial function was applied to the observed PTA concentration over time for each groundwater (Eq. 1):

$$
[\mathrm{PTA}]_{t}=a t^{3}+b t^{2}+c t+d
$$

where $a, b, c$ and $d$ are constants, $t$ is time and [PTA $]_{t}$ is the PTA concentration at time $t$. Datapoints below the limit of quantification were omitted from analysis. Incremental first-order rate constants $\left(k_{\mathrm{obs}}^{\text {incr }}\right)$ were calculated for each sampling point as the derivative of the polynomial, divided by the average PTA concentration at that time:

$$
k_{\mathrm{obs}}^{\mathrm{incr}}=\frac{[\mathrm{PTA}]_{t}{ }^{\prime}}{[\mathrm{PTA}]_{t}} ;[\mathrm{PTA}]_{t}{ }^{\prime}=3 a t^{2}+2 b t+c
$$

where $k_{\text {obs }}^{\text {incr }}$ is the observed incremental rate constant and $[P T A]_{t}{ }^{\prime}$ is the derived polynomial function of degradation over time $(t)$.

The estimated observed incremental degradation rate constants for the studied groundwaters were compared to the rate constants for hydrolytic degradation in pure aqueous solutions, Eq. 1, using the appropriate $\mathrm{pH}$ at the time of sampling in the hydrolysis experiment. In this former study rate-constants were determined at $22{ }^{\circ} \mathrm{C}$. For comparison with the groundwater hydrolysis data obtained at $8{ }^{\circ} \mathrm{C}$, temperature correction is needed to account for temperature dependent changes in reaction kinetics. Hence, the rates at $22{ }^{\circ} \mathrm{C}$ have been retransformed to rates at $8{ }^{\circ} \mathrm{C}$ using the Arrhenius equation:

$$
k_{\text {pred }}=\frac{k_{A}\left[H^{+}\right]+k_{N}+\frac{k_{B} \times k_{W}}{\left[H^{+}\right]}}{\exp \left(\frac{E_{A}}{R} \times\left(\frac{1}{273.15+T}-\frac{1}{295.15}\right)\right)}
$$

where $R=8.314 \mathrm{~J} \mathrm{~K}^{-1} \mathrm{~mol}^{-1}, k_{w}=10^{-14.62}\left(8.1{ }^{\circ} \mathrm{C}\right.$; [18]), $T=$ temperature $\left({ }^{\circ} \mathrm{C}\right)$ and the $\mathrm{pH}$-dependent rate constants are as in Eq. 1 . The activation energy $\left(\underline{E}_{A}\right)$ for PTA degradation is assumed to be equivalent to $74.4 \mathrm{~kJ} \mathrm{~mol}^{-1}$ at all $\mathrm{pH}$ values (data only available for $\mathrm{pH}=4.46$ [17]). The resulting $k_{\text {pred }}$ is calculated for separate temperatures plotted in Fig. 4.

All statistical analysis was made in Microsoft Excel (Microsoft Office 2016, Redmond, Washington, USA).

\section{Results and discussion}

\section{Degradation of PTA in groundwater}

Within the 80-day $(1920 \mathrm{~h})$ study period, the waters of Villingebaek and Varde both had complete degradation of
PTA, while the groundwaters from Ermelund, Hovborg, and Agerbaek had almost complete degradation (Fig. 3). The decrease in PTA concentrations with time could be described by 3rd order polynomium fits (Eq. 1) with $R^{2}>0.98$ throughout the investigated period except for the control which showed no significant degradation of PTA.

The apparent half-life, e.g., the time for half of the initial PTA to degrade, was shortest for the Villingebaek sample with a half-life of 6.5 days ( $156 \mathrm{~h}$; the remaining half-lives were 18 days ( $430 \mathrm{~h}$; Ermelund), 39 days ( $940 \mathrm{~h}$; Hovborg), 39 days ( $940 \mathrm{~h}$; Varde), and 47 days (1130 h; Agerbaek). A clear effect of $\mathrm{pH}$ is seen, with the more alkaline waters showing considerably faster degradation (Figs. 3 and 4). Note also the tendency of higher degradation rates for Hovborg and Varde waters when the $\mathrm{pH}$ in these waters increased after about $600 \mathrm{~h}$. The Control showed very little degradation, with a recovery of $93 \pm 3 \%$ on day 80 (1920 h).

The stability of PTA in the examined groundwater generally fits the model of hydrolysis (Eqs. 1 and 3) rather well as depicted in Fig. 4, where model prediction at different temperatures are shown as function of $\mathrm{pH}$ together with the observed data for the groundwaters. The temperature span from 5.5 to $10.5{ }^{\circ} \mathrm{C}$ is indicative for the conditions prevalent in Danish aquifers. Looking at the individual waters, then some variation can be seen, e.g., for Villingebaek and Varde, where dissipation of PTA initially follows the model of hydrolysis well until 100 and $813 \mathrm{~h}$, respectively. After these time points, degradation proceeds faster than predicted from Eq. 1, and outliers from the model are observed. These observations could be due to specific interactions between PTA and dissolved organic and/or inorganic species [27]. However, the groundwaters were very low in dissolved organic matter. Furthermore, alkaline earth metal cations and transition metal cations appear to have no effect on hydrolysis rates (Additional file 1: Section 1), and hence the major cations $\left(\mathrm{Ca}^{2+}, \mathrm{Mg}^{2+}\right)$ and $\mathrm{Fe}^{2+}$ present in the investigated waters should have no impact on the rates of hydrolysis.

Degradation of PTA in the Control (ultra-pure water) differs significantly from the model prediction. A consistent high recovery in the experiment stands in contrast to the $>50 \%$ degradation predicted by Eq. 1. A similar phenomenon was observed previously for analytical PTA standards and stock. We exclude stabilization of PTA in the Control due to admixed byproducts from the extracted PTA used for spiking as the purity of the extract was high. A buffer was used to control $\mathrm{pH}$ in the hydrolysis study of Ayala-Luis et al. [17], which may indicate that PTA hydrolysis is dependent on ionic strength and possibly specific effects with the buffer medium in addition to $\mathrm{pH}-$ effects which have been reported for 


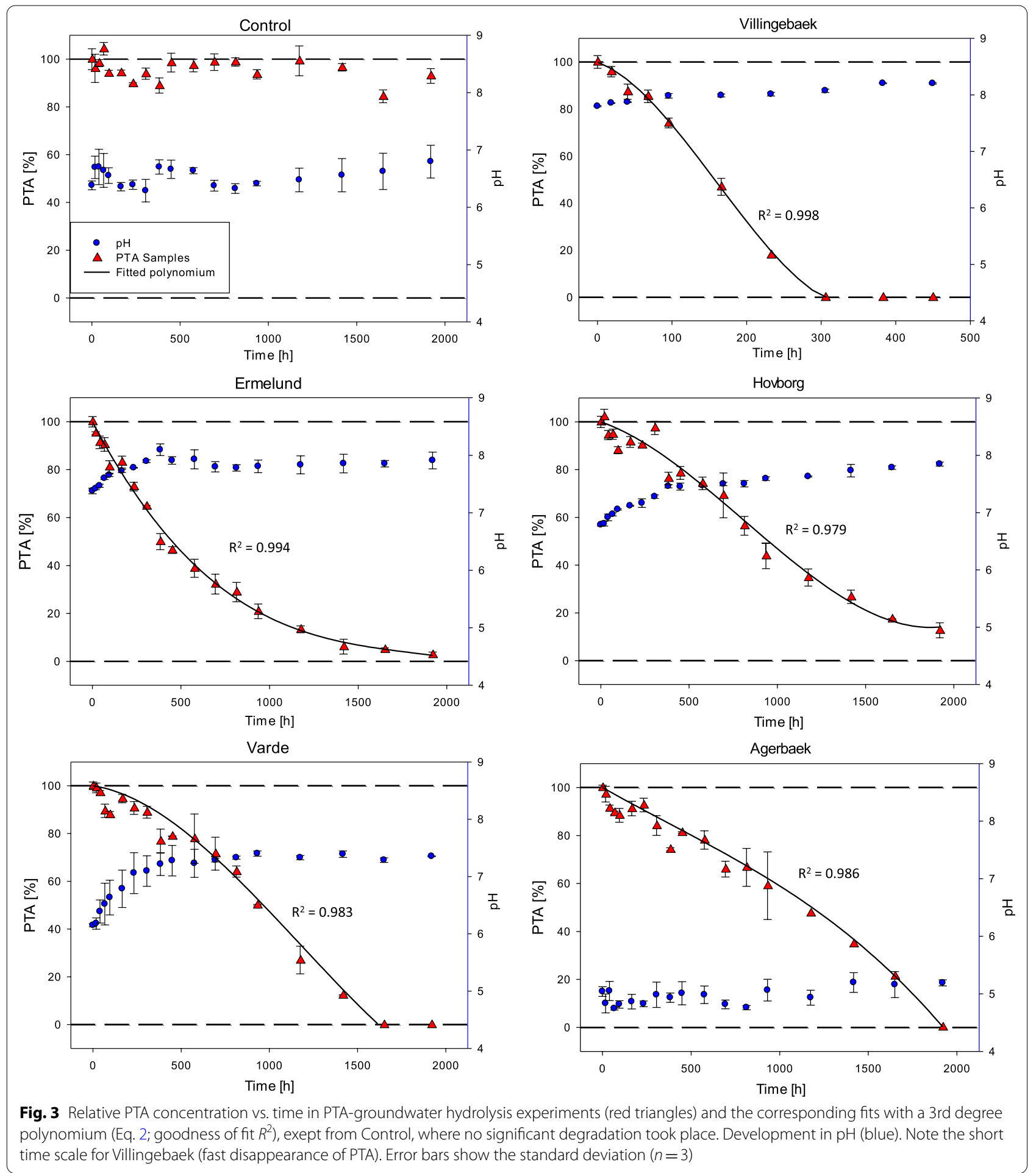

other compounds [28-30]. To test the effect of ionic strength, a small sub-study was made using $\mathrm{NaCl}$ as electrolyte (Additional file 1: Section 2). However, no effect of salt concentration was observed in the salt concentration range of 0.001 to $0.100 \mathrm{M}$ for the two $\mathrm{pH}$ values tested.
Worth to note is also that the hydrolysis rates seen in the ionic strength experiment are consistent with the existing model by Ayala-Luis et al. [17] indicating that specific interactions with buffer medium are non-existing. We cannot exclude that stabilization takes place at very 


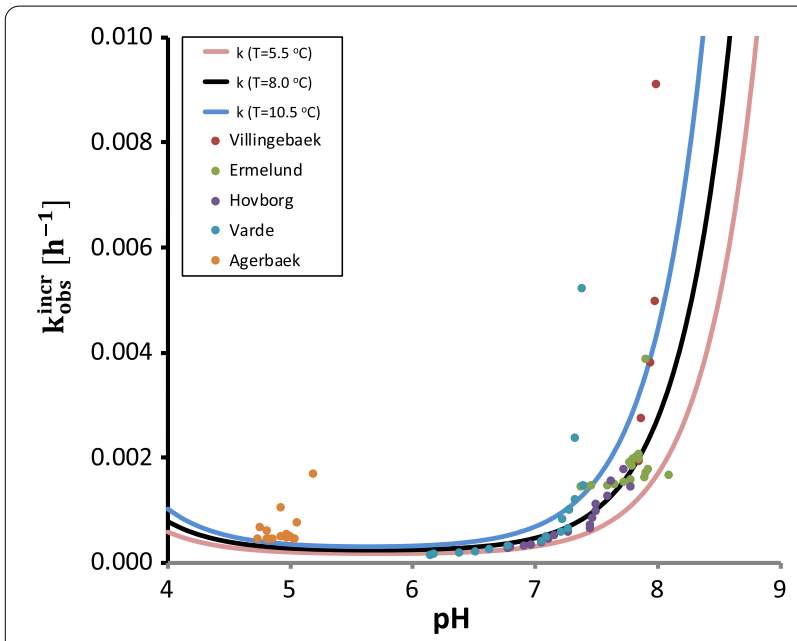

Fig. 4 Observed degradation constant $\left(k_{\text {obs }}^{\text {incr }}\right) v$ s. $\mathrm{pH}$ in groundwaters. Dots represent measured data. Curves show predicted degradation rates from Ayala-Luis et al. [17] at $T=5.5,8.0$ and $10.5^{\circ} \mathrm{C}$

corresponding to experimental conditions. Measurements above the line indicate faster degradation rates than expected and below the line indicate slower degradation rates than expected

low salt concentration stabilizing the cyclopropyl group against nucleophilic attack. Thus, the unexpected stability of PTA in ultrapure water is still to be explained. For practical reasons it may be less important as natural waters always have salt concentrations higher than $0.001 \mathrm{M}$.

Under natural aquifer conditions, minerals such as clays, lime, and quartz will be in contact with the water and the PTA. From soil sorption and stability studies, it is known that PTA is stabilized by clay particles [20]. The present study included no aquifer materials in the reactivity tests. Hence, the observed degradation patterns should be considered a fast tier for PTA degradation. For the aqueous phase itself, then the observed relationship between $\mathrm{pH}$, temperature and $k_{\mathrm{obs}}^{\mathrm{incr}}$ confirms the existing model for PTA hydrolysis in water, although the model appears less accurate under alkaline conditions and for some of the acid samples. Further elucidation of the reaction kinetics in both the alkaline and acid range is needed. In particular, elucidation of the kinetics in the transition area between the slow neutral hydrolysis and the rapid alkaline reactions.

\section{Rate of PTA to PTB conversion}

Figure 5 shows the detected PTA and PTB in the samples analyzed for both compounds plotted vs. the initial PTA concentration for the waters; PTB is shown as PTA-equivalents for direct comparison. The data set includes samples from days 13 to $80(312-1920 \mathrm{~h})$. The slightly alkaline waters of Ermelund and Hovborg in

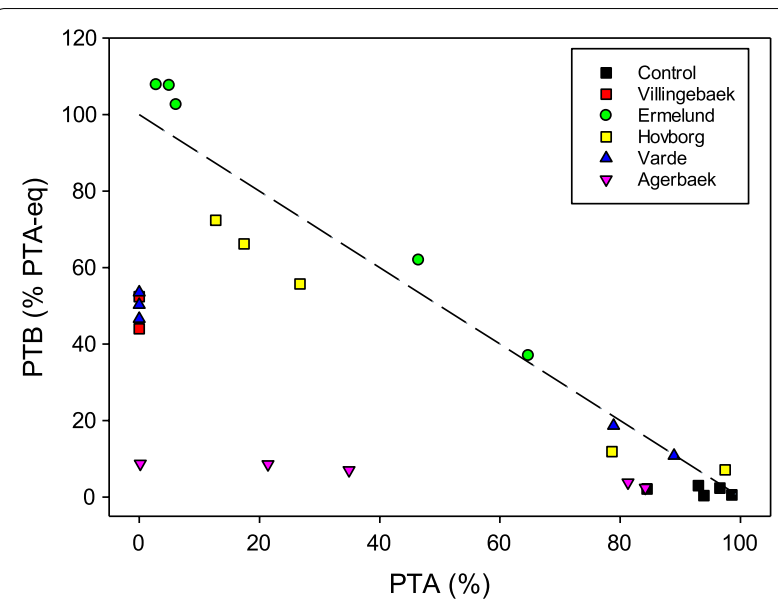

Fig. 5 PTB vs. PTA detected in samples at different time points in the degradation experiment relative to the concentration at start for each of the waters. The solid line marks a 1:1 conversion from PTA to PTB. Relative standard deviation (quality control standards) was $<7 \%$. At Villingebæk, the squares are on top of each other

this time period follow the 1:1 conversion well, and linear regression of these two combined yields a slope of -1.02 and an intercept of $1.00\left(R^{2}=0.89\right)$. The more $\mathrm{pH}$ neutral Varde seemingly starts out similarly to Ermelund and Hovborg but ends with only about $50 \%$ conversion of PTA to PTB. At Villingebaek, the most alkaline of the waters, all PTA degraded with a conversion rate to PTB of only $50 \%$ indicating other reaction pathways and/or presence of stable reaction intermediates like the bracken dienone which is stable under alkaline conditions (Fig. 1). The slightly acidic Agerbaek water behaves different than any of the other waters, as degradation results in formation of small amounts of PTB (about 9\%). The lower extent of PTB formation in Varde and Agerbaek is like what has been observed by Ayala-Luis et al. [17] for the $\mathrm{pH}$ ranges of these waters pointing to formation of other reaction products [1]. Intermediates were observed under laboratory conditions in studies of PTA degradation in surface waters and rapid biological sand filters by Kisielius and co-workers and Skrbic et al. in 2020 [15, 31]. PTB is generally assumed to be more stable than PTA but degrades rapidly in soils due to microbial activity [32]. However, PTB as well as other pterosins have been found in a range of surface waters, soil water as well as shallow groundwater [11-15]. The groundwaters included in this study did not exhibit microbial activity. Hence, the lack of PTB in the samples can be ascribed to formation of PTA intermediates that did not react into PTB within the duration of the experiments as indicated by Skrbic et al. [31]. As expected, the Control showed very little PTB, underscoring the stability of PTA in pure water. Taken together, the results indicate that PTB is formed at a near 
1:1 conversion ratio from PTA when neutral to alkaline reaction dominates $(\mathrm{pH}>6.39)$. At more acidic conditions, other unclarified reaction pathways seem to be at play, which was also suggested by Ayala Luis et al. [17].

The results from this study indicate that PTA can exist for long time periods in groundwater aquifers. PTA will not exist for long in calcareous aquifers as $\mathrm{pH}>8$. Similar conditions prevail in acid aquifers. But in aquifers with $\mathrm{pH}$ 6-7, and in particular shallow aquifers affected by seepage water and influenced by rain mediated preferential flow patterns and incidents in cooler regions, then PTA may be a drinking water contaminant in areas with bracken dominated land [11, 14, 15, 17].

PTA is also present in other ferns than bracken (e.g., Cheilanthes, Dryopteris, and Pteris). Hence, PTA distribution in the environment is potentially larger than can be expected when looking at bracken alone. In addition, compounds similar to PTA should be included in groundwater risk assessment due to their observed or potential presence in drinking water resources, e.g., caudatoside and hypoloside $[14,15]$. To conclude, contamination of drinking water with PTA and PTA-like compounds from many fern species is plausible and requires further insight.

\section{Conclusions}

Based on the experiments presented in this paper, it can be concluded that:

- PTA can be stable in natural groundwaters for months under slightly acid to neutral pH conditions, and $\mathrm{pH}$ is a key factor determining PTA stability with PTA being most stable in slightly acidic groundwater.

- The rate of PTA hydrolysis in groundwaters were well predicted by the rate model developed for buffered laboratory waters except for alkaline and some acid waters, where observed PTA hydrolysis were faster than predicted.

- PTA was found to convert to PTB in a 1:1 ratio in most samples, but with significant deviations from this under acid conditions, indicating formation of other reaction intermediates and products.

Hence, PTA can prevail for months under slightly acid to neutral $\mathrm{pH}$ conditions. Degradation of PTA in groundwater is determined by $\mathrm{pH}$ - and temperature, as explained by the existing model of hydrolysis. The model is generally applicable for groundwaters but needs further validation at high and low $\mathrm{pH}$. Future studies should include a larger variety of groundwaters with larger variation in $\mathrm{pH}$ and groundwater chemistry making it possible to test effect of variables using multivariate statistical analyses, incl. effect of environmental PTA concentrations.

\section{Supplementary information}

The online version contains supplementary material available at https://doi. org/10.1186/s12302-021-00468-0.

Additional file 1: Section 1. Cation effect on the stability of PTA at pH 7.5. Section 2. Effect of ionic strength on the stability of PTA at pH 3.1 and 6.0.

\section{Abbreviations}

HPLC: High performance liquid chromatography; IS: Ionic strength; LC: Liquid chromatography; LOD: Limit of determination; LOQ: Limit of quantification; MS: Mass spectrometry; PTA: Ptaquiloside; PTB: Pterosin B.

\section{Acknowledgements}

The authors wish to thank Laboratory Technician Pernille Sebnem Salvarli for assisting with the microbiological part of the study.

\section{Authors' contributions}

JSW: conceptualization, methodology, investigation, writing-original draft FCK: conceptualization, writing-review and editing. DNL: investigation, writing-review. LHR: conceptualization, methodology, investigation, writingreview and editing. FCK: conceptualization, writing-review and editing BWS: conceptualization, methodology, writing-review and editing. $\mathrm{HCBH}$ : conceptualization, methodology, investigation, writing-review and editing. All authors read and approved the final manuscript.

Funding

The research was funded by University of Copenhagen and University College Copenhagen.

\section{Availability of data and materials}

All data generated or analyzed are available upon request.

Ethics approval and consent to participate

Not applicable.

Consent for publication

Not applicable.

\section{Competing interests}

The authors declare that they have no competing interests.

\section{Author details}

${ }^{1}$ Department of Plant and Environmental Sciences, University of Copenhagen, Thorvaldsensvej 40, 1871 Frederiksberg, Denmark. ${ }^{2}$ Department of Technology, University College Copenhagen, Sigurdsgade 26, 2200 Copenhagen, Denmark.

Received: 22 December 2020 Accepted: 15 February 2021

Published online: 25 February 2021

References

1. O'Connor PJ, Alonso-Amelot ME, Roberts SA, Povey AC (2019) The role of bracken fern illudanes in bracken fern-induced toxicities. Mutat Res 782:108276. https://doi.org/10.1016/j.mrrev.2019.05.001

2. Gil da Costa RM, Bastos MMSM, Oliveira PA, Lopes C (2012) Brackenassociated human and animal health hazards: chemical, biological and pathological evidence. J Hazard Mater 203-204:1-12

3. Saito K, Nagao T, Matoba M, Koyama K, Natori S, Murakami T, Saiki Y (1989) Chemical assay of ptaquiloside, the carcinogen of Pteridium aquilinum, and the distribution of related compounds in the Pteridaceae. Phytochemistry 28:1605-1611 
4. WHO/IARC (2020) International Agency for Research on Cancer (IARC) Summaries \& Evaluations. Bracken fern (Pteridium aquilinum) and some of its constituents (1998). http://www.iarc.fr Accessed 20 Dec 2020.

5. Marrs RH, Watt AS (2006) Biological flora of the British Isles: Pteridium aquilinum (L.) Kuhn. J Ecol 94:1272-1321

6. Ramwell C, van Beinum W, Rowbotham A, Parry H, Parsons S, Luo W, Evans G (2010) Ptaquiloside \& other bracken toxins: a preliminary risk assessment. The Food and Environment Research Agency, Sand Hutton, p 86

7. Rasmussen LH, Donnelly E, Strobel BW, Holm PE, Hansen HCB (2015) Land management of bracken needs to account for bracken carcinogens - a case study from Britain. J Environ Manage 151:258-266

8. Aranha PCDR, Rasmussen LH, Wolf-Jäckel GA, Jensen HME, Hansen HCB, Friis C (2019) Fate of ptaquiloside-A bracken fern toxin-In cattle. PLoS ONE 14(6):e0218628. https://doi.org/10.1371/journal.pone.0218628

9. Rasmussen LH, Schmidt B, Sheffield E (2013) Ptaquiloside in bracken spores from Britain. Chemosphere 90(10):2539-2541. https://doi. org/10.1016/j.chemosphere.2012.10.092

10. Clauson-Kaas F, Ramwell C, Hansen HCB, Strobel BW (2016) Ptaquiloside from bracken in stream water at base flow and during storm events. Water Res 106:155-162

11. Garcia-Jorgensen DB, Diamantopoulos E, Kisielius V, Rosenfield M, Rasmussen LH, Strobel BW, Hansen HCB (2020) Bracken growth, toxin production and transfer from plant to soil - A two-year monitoring study. Submitted to Environmental Science Europe 20 December 2020.

12. Clauson-Kaas F, Jensen PH, Jacobsen OS, Juhler RK, Hansen HCB (2014) The naturally occurring carcinogen ptaquiloside is present in groundwater below bracken vegetation. Environ Toxicol Chem 33:1030-1034

13. O'Driscoll C, Ramwell C, Harhen B, Morrison L, Clauson-Kaas F, Hansen HCB, Campbell G, Misstear B, Pilla F, Xiao L (2016) Ptaquiloside in Irish bracken ferns and receiving waters, with implications for land managers. Molecules. https://doi.org/10.3390/molecules21050543

14. Skrbic N, Kisielius V, Pedersen AK, Christensen SC, Hedegaard MJ, Hansen HCB, Rasmussen LH (2020) Occurrence of carcinogenic illudane glycosides in drinking water wells. Environ Sci Eur. https://doi.org/10.21203/ rs.3.rs-103108/v1

15. Kisielius V, Drejer M, Skrbic N, Dornhoff JK, Lindqvist DN, Hansen HCB, Rasmussen LH (2020) Stability of ptesculentoside, caudatoside and ptaquiloside from bracken ferns in surface waters. Submitted to Environmental Science: Processes and Impacts 20 December 2020

16. Rasmussen LH (2003) Ptaquiloside-an environmental hazard? PhD-thesis, Chemistry Department. The Royal Veterinary and Agricultural University, Denmark

17. Ayala-Luis KB, Hansen PB, Rasmussen LH, Hansen HCB (2006) Kinetics of ptaquiloside hydrolysis in aqueous solution. Environ Toxicol Chem 25:2623-2629

18. Schwarzenbach RP, Gschwend PM, Imboden DM (2003) Environmental organic chemistry. Wiley-Interscience, Hoboken

19. Ovesen RG, Rasmussen $L H$, Hansen HCB (2008) Degradation kinetics of ptaquiloside in soil and soil solution. Environ Toxicol Chem 27:252-259
20. Rasmussen LH, Hansen HCB, Lauren D (2005) Sorption, degradation and mobility of ptaquiloside, a carcinogenic Bracken (Pteridium sp.) constituent, in the soil environment. Chemosphere 58:823-835

21. Skrbic N, Pedersen AK, Christensen SCB, Hansen HCB, Rasmussen LH (2020) A novel method for determination of the natural toxin ptaquiloside in ground and drinking water. Water 12:2852. https://doi. org/10.3390/w12102852

22. Clauson-Kaas F, Hansen HCB, Strobel BW (2016) UPLC-MS/MS determination of ptaquiloside and pterosin B in preserved natural water. Anal Bioanal Chem 408:7981-7990

23. Aranha PCR, Hansen HCB, Rasmussen LH, Strobel BW, Friis C (2014) Determination of ptaquiloside and pterosin $B$ derived from bracken (Pteridium aquilinum) in cattle plasma, urine and milk. J Chromatogr B 951-952:44-51

24. Rasmussen LH, Pedersen HA (2017) Screening for ptaquiloside in ferns: Using herbarium specimens for qualitative mapping purposes. Phytochem Anal 28:575-583. https://doi.org/10.1002/pca.2707

25. GEUS (2016). Jupiter database. http://www.geus.dk. Accessed 15 Mar 2016.

26. NKML (Nordisk Metodikkomite for Næringsmidler) (2013) Aerobic microorganisms. Determination in foods at $37^{\circ} \mathrm{C}, 30^{\circ} \mathrm{C}, 25^{\circ} \mathrm{C}, 20^{\circ} \mathrm{C}, 17 / 7^{\circ} \mathrm{C}$ or $6.5^{\circ} \mathrm{C}$ by the colony count method, 5th edn. NKML, Mørkhøj

27. Ojika M, Wakamatsu K, Niwa H, Yamada K (1987) Ptaquiloside, a potent carcinogen isolated from bracken fern Pteridium aquilinum var. latiusculum: structure elucidation based on chemical and spectral evidence, and reactions with amino acids, nucleosides, and nucleotides. Tetrahedron 43(22):5261-5274. https://doi.org/10.1016/50040-4020(01)87702-4

28. Stefano CD, Foti C, Gianguzza A, Marrone F, Sammartano S (1999) Hydrolysis of methyltin (IV) trichloride in aqueous $\mathrm{NaCl}$ and $\mathrm{NaNO} 3$ solutions at different ionic strengths and temperatures. Appl Organomet Chem 13:805-811

29. Loftin KA, Adams CD, Meyer MT, Surampalli R (2008) Effects of ionic strength, temperature, and $\mathrm{pH}$ on degradation of selected antibiotics. J Environ Qual 37:378-386

30. Skourti-Stathaki E, Clauson-Kaas F, Brandt KK, Rasmussen LH, Hansen HCB (2016) Dissipation of pterosin B in acid soils - tracking the fate of the bracken fern carcinogen ptaquiloside. Chemosphere 165:453-459

31. Skrbic N, Hama J, Strobel BW, Hansen HCB, Rasmussen LH, Pedersen AK, Christensen SCB, Hedegaard MJ (2021) Removal of phytotoxins in filter sand from biological rapid sand filters for drinking water treatment. To be submitted to Water Research 31 December 2020.

32. Pang K, Zhao H, Hu J (2020) Hydrolysis of amisulbrom in buffer solutions and natural water samples: Kinetics and products identification. Bull Environ Contam Toxicol 104:689-700. https://doi.org/10.1007/s0012 8-020-02838-5

\section{Publisher's Note}

Springer Nature remains neutral with regard to jurisdictional claims in published maps and institutional affiliations.

\section{Submit your manuscript to a SpringerOpen ${ }^{\circ}$ journal and benefit from:}

- Convenient online submission

- Rigorous peer review

- Open access: articles freely available online

- High visibility within the field

- Retaining the copyright to your article

Submit your next manuscript at $\boldsymbol{\nabla}$ springeropen.com 